\title{
FILTER BAND PASS MIKROSTRIP DENGAN STEPPED IMPEDANCE RESONATOR (SIR) UNTUK SYNTHETIC APERTURE RADAR (SAR) L-BAND
}

\author{
Narulita Fubian', Heroe Wijanto², Desti Madya Saputri ${ }^{3}$ \\ 1, 2, ${ }^{3}$ Fakultas Teknik Elektro, Universitas Telkom \\ 1narulitafubian@student.telkomuniversity.ac.id, 2heroe@telkomuniversity.ac.id, \\ 3destimadyasaputri@telkomuniversity.ac.id
}

\begin{abstract}
Abstrak
Filter pada teknologi synthetic aperture radar (SAR) digunakan untuk menghilangkan interferensi dan frekuensi lain yang tidak diinginkan pada saat modulasi. Hasil penginderaan yang baik dihasilkan oleh filter band pass yang dapat melewatkan frekuensi yang diinginkan dan memotong frekuensi yang tidak diharapkan. Oleh karena itu, pada penelitian ini filter dirancang dengan selektivitas yang tinggi, yakni pada frekuensi 1,27 GHz dengan lebar pita sebesar $10 \mathrm{MHz}$. Rancangan resonator yang digunakan adalah stepped impedance resonator (SIR) yang berbentuk ring kotak karena dapat menghasilkan lebar pita yang sempit. Bahan yang digunakan untuk implementasi filter ini adalah duroid RT-5880 dengan konstanta dielektrik 2,2. Hasil perancangan menunjukkan bahwa respon frekuensi pada 1,27 $\mathbf{G H z}$ memiliki nilai return loss (S11) -19,95 dB dan nilai insertion loss (S21) -0,97 dB. Untuk lebar pita pada rentang frekuensi 1,265-1,275 GHz didapatkan nilai S11 dan S21 secara berurutan sebedar $\mathbf{- 1 5 , 5 4}$ dB dan $\mathbf{- 0 , 9 9}$ dB serta $14,68 \mathrm{~dB}$ dan $-1,09 \mathrm{~dB}$.
\end{abstract}

Kata Kunci: band pass filter, stepped impedance resonator, duroid RT-5880

\section{Abstract}

Filter in synthetic aperture radar (SAR) is used to remove interference and other unexpected frequencies during modulation. Good sensing results obtained by band pass filter which pass the desired frequency and cut the unexpected frequency. In this study the filter is designed with high selectivity, at a frequency of 1.27 GHz with a bandwidth of $10 \mathrm{MHz}$. The resonator used in this paper is a stepped impedance resonator in a squared ring shape because it can produce narrow bandwidth. The material used in this filter is the duroid RT-5880 which has a dielectric constant of 2.2. The results confirmed frequency response at $1.27 \mathrm{GHz}$ with S11 value of $-19.95 \mathrm{~dB}$ and $\mathrm{S} 21$ value of $-0.97 \mathrm{~dB}$. For bandwidths in the frequency range 1.265-1.275 $\mathrm{GHz}$ we get $\mathrm{S} 11$ and $\mathrm{S} 21$ values $-\mathbf{1 5 . 5 4} \mathrm{dB}$ and $-0.99 \mathrm{~dB}$ and $-14.68 \mathrm{~dB}$ and $-1.09 \mathrm{~dB}$ respectively.

Keywords: band pass filter, stepped impedance resonator, duroid RT-5880

\section{Pendahuluan}

Salah satu teknologi yang sedang berkembang pada saat ini adalah teknologi penginderaan jarak jauh (remote sensing). Penginderaan jarak jauh sangat membantu dalam pengambilan sebuah data karena teknologi ini dapat dipakai dalam wilayah dengan cakupan luas dan dapat menghemat waktu.

Pengambilan sebuah data dapat dilakukan dengan menggunakan pesawat tanpa awak atau yang lebih dikenal dengan drone dan sebuah satelit. Drone tidak terlalu banyak dipakai dibandingkan dengan satelit karena teknologi satelit memiliki cakupan yang lebih luas [19]. Dalam teknologi satelit, penginderaan jarak jauh dilakukan menggunakan teknologi kamera untuk dapat melihat bentuk bumi secara berkala. Walaupun dapat melihat bentuk bumi, teknologi kamera memiliki sebuah kelemahan, yaitu bila daerah yang ingin dipetakan tertutup oleh awan dan dalam keadaan yang gelap. Oleh karena itu dikembangkan lagi sebuah teknologi yaitu SAR yang menggunakan gelombang radio sebagai sarana dalam pengambilan data dan remote sensing [5].

Untuk menjaga kestabilan lebar pita keluaran dari pembangkit sinyal Chrip pada sistem SAR, dibutuhkan filter gelombang mikro. SAR menggunakan filter gelombang mikro berupa band pass filter dengan respon chebyshev sehingga dapat melewatkan frekuensi yang diinginkan saja dan menghilangkan frekuensi lainnya. Lebar pita yang digunakan untuk dapat melewatkan data yang diambil relatif sempit, yaitu sebesar $10 \mathrm{MHz}$ pada daerah kerja $1,265 \mathrm{GHz}-1,275 \mathrm{GHz}$ sesuai dengan spesifikasi dari penelitian [8,9], karena semakin sempit lebar pita, maka resolusi akan semakin besar. Filter gelombang mikro dengan menggunakan aluran mikrostrip dipilih karena bentuk yang simpel dan lebih mudah untuk dioptimisasi.

Penelitian ini menggunakan metode SIR berbentuk ring. Pemilihan model ini bertujuan untuk mendapatkan lebar pita yang sempit berdasarkan beberapa penelitian sebelumnya. Karakteristik pita

Filter Band Pass Mikrostrip denan Stepped Impedance Resonator (SIR) untuk Synthetic Aperture Radar 
frekuensi yang sempit dari resonator berbentuk ring diharapkan dapat menjadi filter dengan selektivitas tinggi pada frekuensi L. Di Indonesia sendiri, pada frekuensi $\mathrm{L}$ terdapat rentang frekuensi radio amatir antara 1260-1300 MHz [16]. Dengan rentang frekuensi tersebut, penelitian ini hanya menggunakan lebar pita sebesar $10 \mathrm{MHz}$ karena diharapkan sistem SAR yang akan dirancang memiliki resolusi yang tinggi.

Pada penelitian [7] digunakan parallel-coupled stepped impedance resonators untuk menghasilkan rejection bandwidth yang optimal. Penelitian [5] merancang sebuah filter dengan metode modifikasi terhadap open loop squared ring resonator dengan penambahan edge coupled to input/output lines dengan frekuensi kerja $1,272 \mathrm{GHz}$ menggunakan bahan duroid RT-5880 yang memiliki konstanta dielektrik sebesar 2,2. Dari hasil pengukuran dengan metode tersebut nilai bandwidth filter yang dihasilkan sebesar $22 \mathrm{MHz}$. Selanjutnya, penelitian [14] juga menggunakan bentuk ring disertai loop terbuka dengan tujuan untuk meminiaturisasi dimensi filter dengan respon pita frekuensi yang sempit.

\section{Synthetic Aperture Radar (SAR)}

SAR adalah suatu jenis modifikasi sistem radar untuk menghasilkan citra sebagai pengganti tampilan jarak (range) dan arah. Sistem ini dapat dioperasikan pada malam hari atau melewati tutupan awan yang tebal [12].

Secara umum sistem SAR tersusun oleh transmitter, receiver, onboard signal processing, $S$ band transmitter dan ground station. Transmitter terdiri dari chirp generator, band pass filter (BPF), local oscilator (LO), power amplifier (PA), switch untuk pemilihan jenis polarisasi antena dan antena pengirim dengan polarisasi sirkular. Di dalam transmitter ini sinyal diproses dan kemudian dikirimkan oleh antena pengirim yang akan mengenai permukaan bumi [15].

Pembangkit sinyal chrip generator berfungsi sebagai sinyal pemancar yang dikirimkan ke objek yang ingin diketahui. Semakin detail objek yang ingin diketahui atau diamati, maka resolusi yang harus dimiliki oleh sistem SAR harus semakin besar. Resolusi ini berhubungan terbalik dengan lebar pita sistem SAR yang dikembangkan [13].

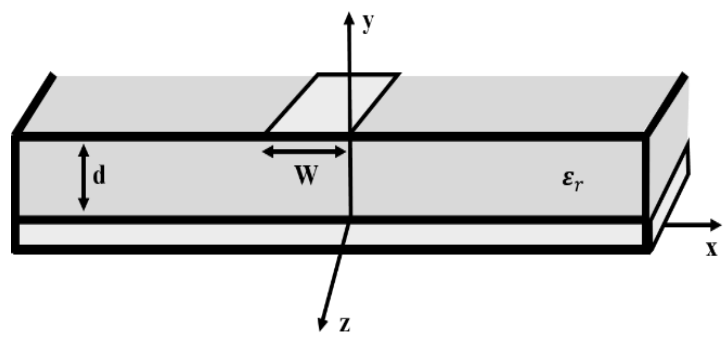

Gambar 1. Struktur saluran mikrostrip
Setelah mengenai permukaan bumi, sinyal akan dipantulkan kembali dan diterima oleh antena penerima dengan polarisasi sirkular pada bagian receiver, yang selanjutnya diproses kembali oleh low noise amplifier (LNA), band pass filter (BPF), I/Q demodulator, analog to digital converter (ADC), temporary memory, onboard signal processing (OSP) dan data dikirimkan ke ground station oleh S-band transmitter $[2,8]$.

\section{Filter [1]}

Filter merupakan suatu perangkat yang dirancang dengan kemampuan untuk dapat melewatkan sinyal dengan band frekuensi terentu dan meredam sinyal di luar band tersebut. Jenis filter dibagi berdasarkan letak yaitu passband dan stopband. Passband adalah daerah frekuensi yang dapat dilewati oleh sinyal, sedangakan stopband adalah daerah frekuensi yang tidak dapat dilewati sinyal atau diredam oleh filter. Daerah passband dibatasi oleh frekuensi cut off, yaitu frekuensi sinyal dimana pada frekuensi tersebut daya turun setengah kali dari daya sinyal atau sebesar $3 \mathrm{~dB}$ dari frekuensi passband.

Berdasarkan daerah passband dan stopbandnya, filter dapat dibagi menjadi 4, yaitu:

- Low Pass Filter (LPF), yaitu filter yang letak passband-nya berada pada frekuensi rendah.

- High Pass Filter (HPF), yaitu filter yang letak passband $\neg$-nya berada pada frekuensi tinggi.

- Band Pass Filter (BPF), yaitu filter yang letak passband-nya berada di antara frekuensi cut off.

- Band Stop Filter (BSF), yaitu filter yang letak stopband-nya berada di antar frekuensi cut off.

Proses perancangan filter dengan mengunakan induktor dan kapasitor dilakukan dengan cara mendefinisikan spesifikasi frekuensi yang ingin diloloskan dan diredam, kemudian merancang filter pelolos frekuensi rendah yang ternormalisasi. Dari filter pelolos frekuensi rendah yang ternormalisasi, dapat diubah menjadi filter ternormalisasi lainnya seperti pelolos frekuensi tinggi atau pelolos frekuensi tengah. Dari filter ternormalisasi yang diinginkan tersebut, kemudian didenormalisasi untuk mendapatkan nilai komponen induktor dan kapasitor [3]. Untuk perancangan menggunakan prinsip saluran transmisi dapat menggunakan identitas Kuroda dan transformasi Richard [1]. Kedua langkah tersebut memanfaatkan sifat induktif dan kapasitif dari saluran dengan beban yang dihubung singkat (short circuit) atau dibiarkan terbuka (open circuit).

\section{Saluran Mikrostrip}

Mikrostrip merupakan saluran transmisi yang terdiri dari konduktor strip (line) dan sebuah konduktor bidang tanah yang dipisahkan oleh medium dielektrik dengan konstanta dielektrik $\varepsilon_{r}$. Pada saluran mikrostrip terdapat dua medium yang 
berbeda yaitu udara dengan konstanta dielektrik $\left(\varepsilon_{r}\right)$ sebesar 1 dan bahan dielektrik lain $\left(\varepsilon_{r}\right)>1$. Konstanta dielektrik disebut juga konstanta dielektrik efektif $\left(\varepsilon_{f f}\right)$. Media di atas strip adalah udara, tanpa adanya shielding sebagian medan elektromagnetik akan meradiasi dan sebagian lagi ada yang masuk kembali ke dalam substrat dielektrik [20].

Saluran mikrostrip adalah jenis saluran yang populer digunakan karena mudah untuk diminiaturisasi serta mudah diintegrasikan dengan komponen gelombang mikro pasif ataupun aktif. Gambar 1 merupakan struktur dari saluran mikrostrip [3].

Desain dimensi saluran mikrostrip dapat menggunakan persamaan 1-9 [6, 20].

$$
\varepsilon_{e}=\frac{\varepsilon_{r}+1}{2}+\frac{\varepsilon_{r}-1}{2}\left[1+\frac{10}{\frac{W}{d}}\right]^{-(a c)}
$$

dengan:

$$
\left[\left(\frac{w}{d}\right)^{4}+\left(\frac{\frac{w}{d}}{52}\right)^{2}\right] \quad \begin{array}{ll}
d & \pi\left[\frac{\varepsilon_{r-1}}{2 \varepsilon_{r}}\left(\ln (B-1)+0,39-\frac{0,61}{\varepsilon_{r}}\right)\right] \\
, \frac{W}{d}>2 . &
\end{array}
$$

dengan:

$$
\begin{gathered}
A=\frac{Z_{0}}{60} \sqrt{\frac{\varepsilon_{r}+1}{2}}+\frac{\varepsilon_{r}-1}{\varepsilon_{r}+1}\left(0,23+\frac{0,11}{\varepsilon_{r}}\right) \\
B=\frac{377 \pi}{2 Z_{0} \sqrt{\varepsilon_{r}}}
\end{gathered}
$$

\section{Stepped Impedance Resonator (SIR) [7]}

SIR merupakan resonator yang berupa saluran transmisi dengan impedansi karakteristik berubah secara bertahap sesuai panjang saluran.

SIR terbukti dapat digunakan dalam merancang mikrostrip band pass filter dengan kinerja stop band yang baik. Salah satu fitur utama dari SIR adalah frekuensi resonannya dapat diatur dengan menyesuaikan dengan parameter struktural, seperti rasio impedansi di segmen tinggi dan rendah. Gambar 2 merupakan struktur dari SIR.

Panjang saluran resonator pada SIR ring resonator adalah sebesar $\lambda / 4$. Besar $\lambda$ dapat diperoleh menggunakan perhitungan dari persamaan yang umum dipakai pada saluran transmisi. Nilai $\lambda$ pada saluran transmisi mikrostrip adalah $\lambda_{0}$ yang dipengaruhi oleh besarnya konstanta dielektrik efektif substrat, dapat menggunakan persamaan 10.

$$
\lambda_{g}=\frac{\lambda_{0}}{\sqrt{\varepsilon_{e}}}=\frac{c}{f_{0} \sqrt{\varepsilon_{e}}}=\frac{c}{\sqrt{f_{1} \times f_{2}} \sqrt{\varepsilon_{e}(R)}} .
$$

Dalam realisasinya, filter SIR tidak hanya memiliki frekuensi fundamental yang diinginkan tetapi juga akan timbul spurious frequency response yang akan merugikan dalam pengimplementasian filter. Adapun cara untuk meminimalisir akibatnya adalah dengan mengatur rasio impedansi.

Gambar 2. Struktur stepped impedance resonator 


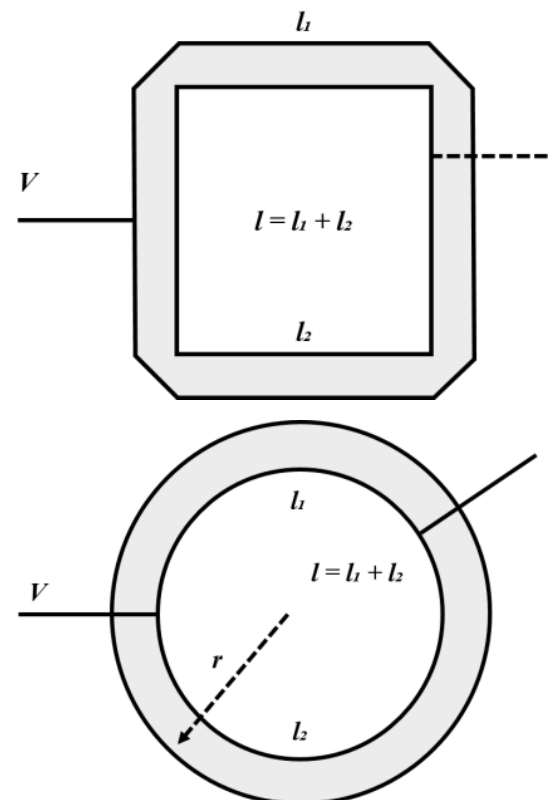

Gambar 3. Struktur ring resonator

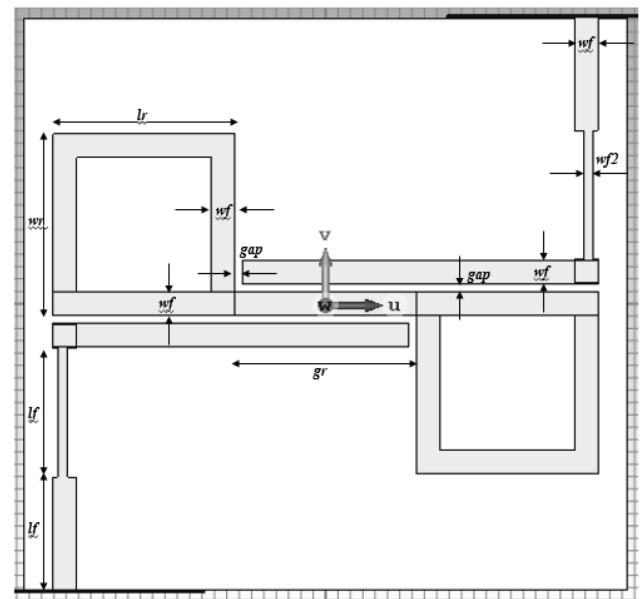

Gambar 4. Desain hasil perhitungan awal

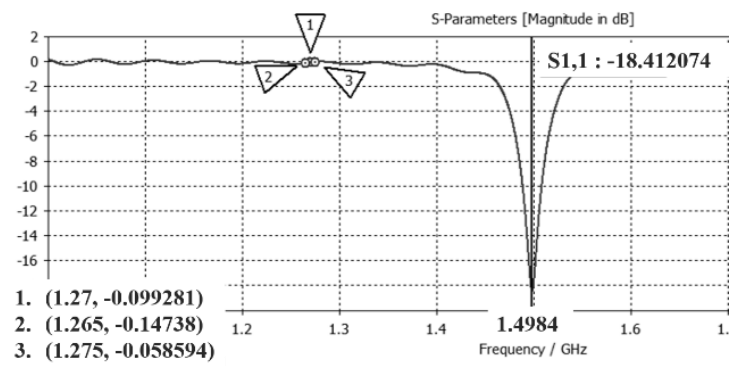

Gambar 5. Hasil simulasi perhitungan awal S11

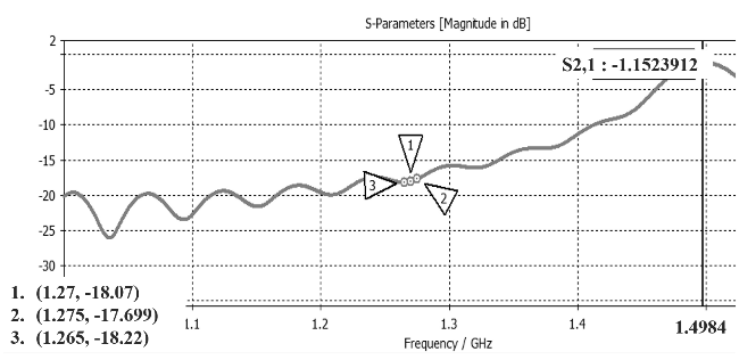

Gambar 6. Hasil simulasi perhitungan awal S21

\section{Squared Ring Resonator}

Resonator berbentuk ring memiliki karakteristik respon frekuensi bandpass. Jika ring resonator dihubungkan ke input saluran transmisi dan output saluran transmisi, sinyal akan melewati/diloloskan ring resonator dengan redaman tertentu pada frekuensi resonansi ring tersebut dan akan ditolak/diredam pada frekuensi di luar frekuensi resonansi. Filter ring resonator juga memiliki respon pita frekuensi lebih sempit jika dibandingkan dengan filter resonator konvensional [2].

Filter dengan metode resonator berbentuk ring, baik kotak ataupun bulat, memiliki bentuk dan rangkaian yang sederhana. Dimensi dari filter ini bernilai sama dengan kelipatan dari jari-jari resonator ring, baik kotak ataupun bulat. Gambar 3 merupakan ring resonator yang memiliki panjang dimensi seperti pada (11) untuk berbentuk kotak dan persamaan 12 untuk berbentuk lingkaran [11].

$$
\begin{aligned}
& l=l_{1}+l_{2}=n l g \\
& l=n \lambda g=2 \pi r
\end{aligned}
$$

Panjang gelombang untuk resonator ring berbentuk lingkaran dapat dicari dengan persamaan 13 [17].

$$
\lambda g=\frac{c}{f \sqrt{\varepsilon_{e}}}
$$

\section{Desain Model Sistem}

Model sistem yang diinginkan dalam perancangan sebuah band pass filter pada penelitian ini adalah memenuhi spesifikasi sebagai berikut:

Frekuensi kerja $\quad: 1,265 \mathrm{GHz}-1,275 \mathrm{GHz}$

Frekuensi tengah $\quad: 1,27 \mathrm{GHz}$

Bandwidth $\quad: 10 \mathrm{MHz}$

Z terminal $\quad: 50 \mathrm{Ohm}$

Insertion pada passband $: \leq-3 \mathrm{~dB}$

Return loss pada passband $: \geq-10 \mathrm{~dB}$

VSWR $\quad: \leq 2$

Respon frekuensi : Chebyshev

Filter yang akan dirancang menggunakan teknik saluran transmisi mikrostrip dengan menggunakan bahan dielektrik yaitu duroid RT-5880. Karakteristik substrat dari duroid RT-5880 adalah sebagai berikut [18]:

Permitivitas dielektrik $\left(\varepsilon_{r}\right): 2,2$

Tebal dielektrik (d) $\quad: 1,575 \mathrm{~mm}$

Tebal konduktor $(\mathrm{t}) \quad: 0,035 \mathrm{~mm}$

Tangent Loss $(\tan \delta) \quad: 0,0009$

\section{Filter Band Pass Mikrostrip}

Frekuensi tengah filter yang diinginkan pada penelitian ini berada pada $1,27 \mathrm{GHz}$ dengan desain awal berupa resonator berbentuk kotak.

Satu buah resonator memiliki panjang sebesar 44,01 mm. Pada penilitian tugas akhir ini akan dibentuk coupled ring squared resonator yang terpisah dengan jarak $\frac{\lambda g}{4}$ dan dibagi menjadi 2 dari besarnya $\frac{\lambda g}{4}$. 
Sehingga besarnya dimensi dengan nilai $\frac{\lambda_{g}}{12}$ adalah 14,67 mm, dan jarak adalah $14,67 \mathrm{~mm}$. Dari parameter tersebut, didesain model filter seperti pada gambar 4 dengan dimensi pada tabel 1 .

Hasil simulasi dari desain awal dapat dilihat pada gambar 5 dan gambar 6. Grafik dengan garis tegas berwarna merah dan hijau adalah hasil dari simulasi perhitungan awal. Merah untuk parameter S11 dan hijau untuk grafik S21.

Pada gambar tersebut desain dari hasil perhitungan belum dapat dikatakan sebagai filter SAR. Parameter tersebut berada pada frekuensi 1,4989 $\mathrm{GHz}$ dengan nilai parameter $\mathrm{S} 11$ sebesar $18,41 \mathrm{~dB}$. Dengan kondisi demikian, desain hasil perhitungan belum sesuai dengan spesifikasi filter yang diharapkan, yaitu dapat meloloskan sinyal dengan frekuensi tengah sebesar $1,27 \mathrm{GHz}$ dan lebar pita sebesar $10 \mathrm{MHz}$, meskipun nilai dari S parameter sudah tercapai.

Dengan hasil awal yang didapat, maka diperlukan optimisasi untuk mendapatkan spesifikasi filter yang sesuai, yaitu frekuensi kerja berada pada 1,27 GHz dan lebar pita sebesar $10 \mathrm{MHz}$. Hasil yang diinginkan dari proses optimisasi adalah nilai return loss, insertion loss, dan vswr minimum terdapat di frekuensi 1,27 GHz, kemudian nilai bandwidth harus sesuai dengan spesifikasi.

Untuk mendapatkan frekuensi yang diinginkan maka perlu mengetahui karakteristik perubahan dari setiap dimensi filter. Dimensi yang paling mempengaruhi perubahan frekuensi adalah panjang resonator $(l r)$. Setelah itu dimensi $l r$ tersebut akan dikombinasikan dengan dimensi lainnya seperti $w r$, $g r$, ,lf, wf, wf2, dan gap sampai filter bekerja di frekuensi tengah 1,27 GHz.

Ukuran dimensi akhir dari filter pada gambar 7 dan tabel 2 merupakan bentuk dimensi yang paling optimal hasilnya menurut simulator setelah melalui beberapa tahap optimisasi yang telah dilakukan.

Dimensi total yang didapatkan untuk membuat filter tersebut sebesar $16 \mathrm{~mm}$ untuk panjang resonator filter, 17,5 mm untuk lebar resonator filter, $0,75 \mathrm{~mm}$ untuk lebar ring resonator serta dan lebar feed bagian atas, serta 0,3 mm untuk lebar feed bagian bawah.

Return Loss (S11) merupakan parameter yang menunjukkan karakteristik sinyal yang dipantulkan kebali menuju sumber. Semakin kecil nilai return loss maka semakin kecil pula daya yang kembali menuju sumber, sehingga daya yang ditransmisikan menuju beban akan semakin maksimal.

Insertion Loss (S21) merupakan parameter filter utama yang menunjukkan karakteristik sinyal yang diterima oleh beban melalui sumber atau sinyal yang ditransmisikan dari Port input ke Port output. Daya yang ditransmisikan filter baiknya sebesar mungkin, agar sinyal yang melewati filter tidak banyak yang teredam.

Dapat dilihat dari gambar 8 bahwa nilai return loss pada frekuensi tengah $1,27 \mathrm{GHz}$ sudah memenuhi spesifikasi yaitu $-20,526 \mathrm{~dB}$. Nilai ini berarti daya yang kembali pada port 1 akibat pencatuan pada port 1 bernilai minimal, sehingga dominan daya akan keluar pada port tetangga, dalam hal ini port 2. Sementara nilai return loss pada range frekuensi 1,265 GHz-1,275 GHz adalah $-15,113 \mathrm{~dB}$ dan $-15,303 \mathrm{~dB}$.

Untuk memastikan daya keluar pada port 2 dan tidak menjadi daya lain dirangkaian, dilakukan dengan melihat parameter S21 seperti pada gambar 9 yang menyatakan keluaran pada port 2 akibat dari pencatuan pada port 1. Pada frekuensi $1,27 \mathrm{GHz}$, nilai parameter S21 bernilai $-0,98 \mathrm{~dB}$ yang artinya, dominan daya keluar ke arah port 2 .

Tabel 1. Dimensi Filter

\begin{tabular}{|l|l|c|}
\hline Variabel & \multicolumn{1}{|c|}{ Keterangan } & Nilai (mm) \\
\hline Ir & Panjang resonator & 14,67 \\
\hline$w r$ & Lebar resonator & 14,67 \\
\hline$g r$ & Panjang resonator tengah & 14,67 \\
\hline$L f$ & Panjang feed & 11 \\
\hline$w f$ & Lebar ring resonator; Lebar feed bagian atas & 2,2 \\
\hline wf2 & Lebar feed bagian bawah & 0,88 \\
\hline gap & Jarak kopling & 0,6 \\
\hline
\end{tabular}

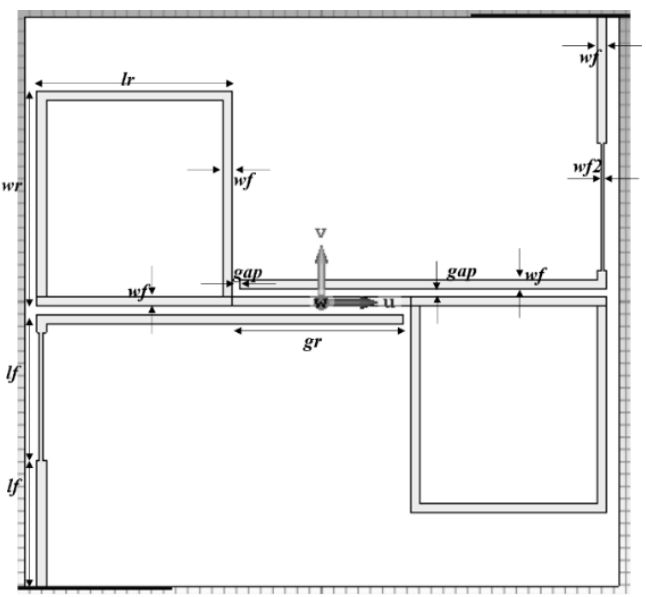

Gambar 7. Desain hasil optimisasi

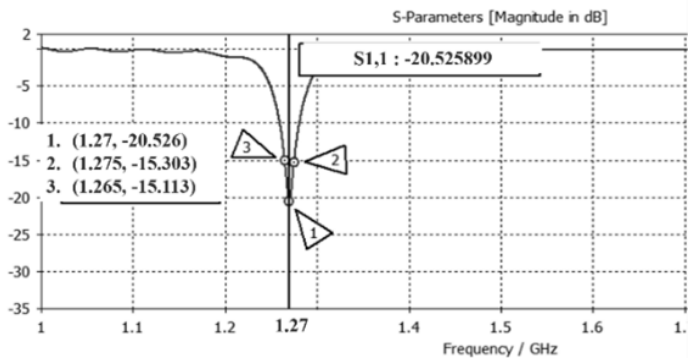

Gambar 8. Hasil optimisasi simulasi S11

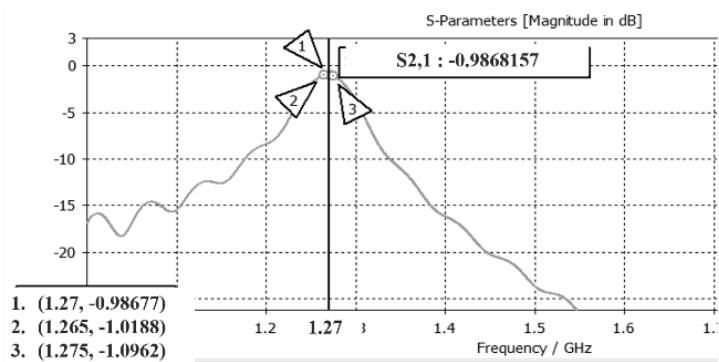

Gambar 9. Hasil optimisasi simulasi S21 
Tabel 2. Dimensi Filter Setelah Opimasi

\begin{tabular}{|l|l|c|}
\hline \multicolumn{1}{|c|}{ Variabel } & \multicolumn{1}{c|}{ Keterangan } & Nilai $(\mathbf{m m})$ \\
\hline$L r$ & Panjang resonator & 16 \\
\hline$W r$ & Lebar resonator & 17,5 \\
\hline$g r$ & Panjang resonator tengah & 14,67 \\
\hline$L f$ & Panjang feed & 11 \\
\hline \multirow{2}{*}{$w f$} & $\begin{array}{l}\text { Lebar ring resonator; Lebar } \\
\text { feed bagian atas }\end{array}$ & 0,75 \\
\hline wf2 & Lebar feed bagian bawah & 0,3 \\
\hline gap & Jarak kopling & 0,6 \\
\hline
\end{tabular}

Sehingga dengan nilai S11 dan S21 tersebut, dapat dikatakan jika filter ini dapat bekerja pada frekuensi $1,27 \mathrm{GHz}$ dengan pantulan daya yang minimum pada port 1 sebagai input dan luaran daya yang maksimum pada port 2 sebagai keluaran.

Untuk melihat lebar pita dari filter yang dirancang, pada frekuensi $1,265 \mathrm{GHz}$ nilai S21 dan S11 sebesar $-1,0188 \mathrm{~dB}$ dan $-15,113 \mathrm{~dB}$ serta pada frekuensi 1,275 nilai S1 1 dan S21 sebesar -15,303 dB dan $-1,09$ dB. Sedangkan jika melihat dari parameter S11 yang dibawah $-10 \mathrm{~dB}$ maka frekuensi berada pada rentang $1,2592 \mathrm{GHz}-1,2802 \mathrm{GHz}$ dan parameter S21 di atas $-3 \mathrm{~dB}$, frekuensi berada pada rentang $1,2412 \mathrm{GHz}-1,2954 \mathrm{GHz}$. Rentang frekuensi pada S21 lebih besar dibandingkan rentang frekuensi pada S11, sehingga jika hanya dibatasi pada frekuensi akibat parameter S11, lebar pita yang didapatkan sebesar $21 \mathrm{MHz}$ dengan S21 yang bersesuaian sebesar $-1,19 \mathrm{~dB}$ dan $-1,36 \mathrm{~dB}$.

Memperhatikan hasil optimisasi dari frekuensi yang diharapkan dengan respon parameter $S$ yang bersesuaian dengan spesifikasi, untuk parameter $S$ yang berada di bawah $-10 \mathrm{~dB}$, terdapat perbedaan lebar pita sebesar $11 \mathrm{MHz}$, yaitu lebar pita sebesar 21 MHz. Lebar pita sebesar $21 \mathrm{MHz}$ ini memiliki performa yang lebih rendah dibandingkan lebar pita sebesar $10 \mathrm{MHz}$ pada frekuensi $1,265 \mathrm{GHz}-1,275$ GHz. Selisih lebar pita sebesar $11 \mathrm{MHz}$ tersebut dapat diartikan bahwa dengan karakteristik pantulan yang sama filter yang telah didesain meloloskan gelombang $11 \mathrm{MHz}$ lebih lebar dari filter yang direncanakan sebesar $10 \mathrm{MHz}$.

\section{Kesimpulan}

Rancangan filter dengan SIR berbentuk ring kotak belum mendapatkan respon frekuensi sesuai spesifikasi filter untuk sistem SAR. Namun dengan optimisasi dimensi filter, didapatkan filter yang bekerja pada frekuensi tengah $1,27 \mathrm{GHz}$ dengan nilai S11 sebesar -20,52 dB dan nilai S21 sebesar -0,98 dB. Untuk lebar pita pada rentang frekuensi 1,265-1,275 $\mathrm{GHz}$ didapatkan nilai S11 dan S21 secara berurutan sebesar $-15,113 \mathrm{~dB}$ dan $-1,01 \mathrm{~dB}$ serta $-15,303 \mathrm{~dB}$ dan $-1,09 \mathrm{~dB}$.

\section{Daftar Pustaka}

[1] C. Bowick, RF Circuit Design, second edition. 2007.

[2] C. C. Yu and K. Chang, "Novel compact elliptic-function narrow-band bandpass filters using microstrip open-loop resonators with coupled and crossing lines," IEEE Trans. Microw. Theory Tech., vol. 46, no. 7, pp. 952958, 1998.

[3] David M. Pozard, Microwave Engineering. Second Edition, John Wiley and sons, 2012.

[4] E. I. M. . Sulaeman, Diktat Kuliah. Program Studi Teknik Telekomunikasi Politekknik Negeri Bandung, 2005.

[5] E. Lumbantobing, B. S. Nugroho, and B. Syihabbudin, "Perancangan Dan Realisasi Filter Dengan Selektivitas Tinggi Pada Band Frekuensi 1 . 27 Ghz," Thesis Telkom University., 2015.

[6] J. H. and M. J. Lancaster, "Couplings of Microstrip Square Open-Loop Resonators for Cross-Coupled Planar Microwaves Filter," vol. 44, no. 12, pp. 2099-2109, 1996.

[7] J. T. Kuo and E. Shih, "Microstrip stepped impedance resonator bandpass filter with an extended optimal rejection bandwidth," IEEE Trans. Microw. Theory Tech., vol. 51, no. 5, pp. 1554-1559, 2003.

[8] J. Tetuko Sri Sumantyo, "Development of Circularly Polarized Synthetic Aperture Radar ( CP-SAR ) Onboard Small Satellite," IEEE International Geoscience and Remote Sensing Symposium, pp. 929-932, 2011.

[9] J. T. S. Sumantyo, "Development Of Circularly Polarized Synthetic Aperture Radar Onboard Unmanned Aerial Vehicle ( CP-SAR UAV )," IEEE International Geoscience and Remote Sensing Symposium, pp. 4762-4765, 2012.

[10] J. T. Sri Sumantyo, "Development of Circulary Polarized Synthetic Aperture Radar Onboard UAV for Earth Diagnosis.," EUSAR., 2012.

[11] K. Chang and L.-H. Hsieh, "Microwave Ring Circuits and Related Structures. Second Edition," A JOHN WILEY SONS, INC., 2004.

[12] K. P. P. iou Moreira, Alberto, Pau Prats-Iraola, Marwan Younis, Gerhard Krieger, Irena Hajnsek, "A Tutorial on Synthetic Aperture Radar," Microwaves Radar Inst. Ger. Aerosp. Cent. (DLR)., 2013.

[13] M. Schultz, "Synthetic Aperture Radar Imaging Simulated in MATLAB," Calif. Polytech. State Univ., 2009.

[14] M. Z. M. Dousti, P. Taheri, S. Sadi, “A Novel Miniaturized Narrow Band Bandpass Filter Utilizing Microstrip Open-loop Ring Resonators for Narrow-band Applications," in Progress in Electromagnetics Research Symposium Proceedings, p. 1415-1419, 2012.

[15] N. Aeni, "Perancangan Dan Realisasi Generator Chirp Pada Synthetic Aperture Radar (SAR)," 2015.

[16] ORARI, “Keputusan Ketua Umum Organisasi Amatir Radio Indonesia Nomor KEP065/OP/KU/2009 tentang Pembagian dan Penggunaan Segmen Band Frekuensi Amatir 
Radio (Bandplan)," 2009, pp. 1-9.

[17] P. V. S. Arain, M. A. B. Abassi, S. Nikolaou, "A square ring resonator bandpass filter with asymmetrically loaded open circuited stubs," in 5th International Conference on Modern Circuits and Systems Technologies, 2016.

[18] R. Corporation, "RT/duroid @ 5870 /5880 Datasheet," 2016.

[19] V. C. Koo et al., "A new unmanned aerial vehicle synthetic aperture radar for environmental monitoring," Prog. Electromagn. Res., vol. 122, no. November 2011, pp. 245-268, 2012.

[20] Y. Fazriyani, "Filter for WiMAX at Band Frequency of $2.3-2.4 \mathrm{GHz}$ using Microstrip Squared Ring Resonator Method," Thesis Telkom Univ., 2008. 